\title{
Implementing faculty computer literacy programs
}

\author{
THOMAS B. PERERA \\ Montclair State College, Upper Montclair, New Jersey
}

\begin{abstract}
A faculty computer literacy grant underwrote distribution and analysis of surveys of faculty computer use and expectations, publication of an extensive newsletter, seminars and workshops, and a computers-on-loan program in which faculty members could take out portable computers like library books. Survey results, successes, and failures are discussed.
\end{abstract}

Many of us have found ourselves to be among the few faculty members on campus with any significant understanding of computer architecture and applications, and have been called upon to help develop academic institutional computing programs, including those for fellow faculty members. In the middle of the fall semester of 1983 , with no warning, I was asked by the college administration to run a faculty development project for which the college had just received a grant of $\$ 6000$. I was to be given complete autonomy and freedom from the pressures of the mathematics and computer-science departments, which were purchasing and attempting to enforce campus-wide standardization on graphicsequipped DEC Rainbow computers and a VAX mainframe. There were no guidelines or restrictions on the expenditure of the funds for the faculty development project, nor could I find any written material on how to develop such a project. In this void of information, I decided on a three-step process, which may be of interest to others who are faced with the same or a similar task.

First, I decided to circulate a detailed questionnaire designed to assess faculty computer knowledge, competence, and expectations. Then I would design a program based on the questionnaire responses, requests, and suggestions. Finally, I would assess the successes and failures of the project with a view toward obtaining future funding and continued grant support.

\section{QUESTIONNAIRE DEVELOPMENT}

As I prepared the initial questionnaire, I realized that it would have to serve a double purpose. For those faculty members who had some computer experience, it would have to ask what hardware and software they had used, determine how extensive their knowledge was, and develop information about what they wanted and expected from the computer literacy project. For the vast majority of faculty members, who had no computer experience,

Copies of the questionnaire and sample copies of the newsletter are available on request from the author at the Department of Psychology, Montclair State College, Upper Montclair, NJ 07043. we had to provide a tutorial, providing simplified, jargonfree information about what computers could do for them, as well as requesting information regarding their expectations and needs.

The final questionnaire requested over 50 responses. I was surprised to find that it was completed by over onethird of the 500-member faculty. This indicated an unusual level of interest and enthusiasm. All of the replies were entered in a large spreadsheet program which allowed for a tally and analysis of the results in many ways without any loss of raw data.

\section{QUESTIONNAIRE RESULTS}

Some of the results were quite predictable, but others were surprising. The vast majority of faculty members had little or no actual experience with computers, but great interest in learning about them. Faculty computer interest was roughly split between Radio Shack and Apple computers; only a few people were interested in other systems, and there was little interest, outside of the mathematics and computer-science departments, in DEC systems. Faculty members who were currently using computers were vehemently loyal to specific brands of computers and would not consider any others. This meant that the entire project had to remain as unbiased as possible with regard to specific types of hardware and software.

Word processing applications were of paramount interest; database management, spreadsheet analysis, statistical analysis, and instructional uses came in as very secondary interests. One series of questions requested information about the kinds of activities that faculty members would prefer the project to provide. Analysis of the answers to these questions showed a very clear dislike for formal lectures, formal workshops, or formal instruction of any kind. Very informal workshops and demonstrations were strongly preferred. It appeared that the faculty were extremely opposed to any form of structured learning experience. Whether this resulted from the classroom instructors' general dislike of classroom instruction or their hesitancy to reveal how little they knew about computers could not be determined. 
The results of this survey were carefully considered and were used as the basis for planning the activities included in the computer literacy project.

\section{WORKSHOPS}

First, I scheduled a series of informal workshops and show-and-tell sessions in which faculty members could watch other faculty members show their computers and demonstrate how to use them. Each session provided six different computers running six different types of programs and a faculty member who demonstrated program operation and answered questions. Also included were a magazine, book, and software show and exchange; discussions on selecting, buying, maintaining, and using computers; users' reports; and open discussions.

These workshops were a disaster. Although a dedicated group of five or six people attended, displayed their computers, and participated actively, no one else attended even though the times were changed each month to fit different schedules. I should have paid more attention to the survey results, which indicated that the faculty did not want to be instructed in computer use.

\section{NEWSLETTER AND DIAL-A-CONSULTANT}

A second attempt to increase faculty knowledge about computing met with considerably more success. I wrote, published, and distributed to each faculty member and administrator a lengthy monthly publication called the Faculty Computing News. In issues varing in length from 17 to 51 pages, the newsletter contained a wide variety of information about computers and computing in the college and local community area.

Each issue of the newsletter started with an editorial that reported on the general status of the grant, the project activities, the survey results, future plans, or important news about the computer field in general. This was followed by a list of special announcements about local computer conventions, computer-related grant opportunities and deadlines, workshops, local computer flea markets, and new discount computer and software purchase agreements. The next section listed all computer-related events in the general area around the college, including local computer-club meeting schedules and special-interestgroup meeting schedules. The next section listed computer-related events on campus. These included workshops, lectures, and formal and informal courses offered by the mathematics and computer-science departments. This was followed by a section listing computer availability on campus. It included room numbers, telephone contact numbers, and hours of availability for every accessible computer and terminal on campus. This section also provided information regarding places on campus to purchase floppy disks and computer supplies and to exchange computer-related books and magazines. The next section provided a list of faculty members willing to assist other faculty members with specific computers and to lend other faculty members various software programs to try out. These were faculty members who had listed their willingness to do this on the questionnaire. The next section of the newsletter listed personalized tutors and a telephone consultant ("Dial-a-consultant") who were available to teach individual faculty members specific software programs or help solve specific problems. These tutors and teleconsultants were paid on an hourly basis by the grant funds. The next section of the newsletter listed all known sources of deep discounts on computer equipment, and comments from faculty members who had purchased from these sources in the past. It also included a monthly computer "flea market" in which faculty members could buy, sell, or trade their computer equipment with other faculty members.

Following these regular sections of the newsletter were one or more longer articles of general interest to faculty members. Topics such as how to select a computer, how to care for diskettes, how to transfer data from any computer to any other via RS-232 or media-exchange software, how to communicate with timesharing networks, and so forth, appeared each month. After these articles, unedited letters from individual faculty members were published, and the last page of the newsletter always included a form for sending in comments, criticisms, and suggestions. Most of the comments dealt with the college's unilateral decision to purchase DEC Rainbow computers as the "campus computer," the subsequent cancellation of the Rainbow from DEC's product line, and heated arguments about the merits of one brand of computer or another.

The newsletter was a definite success. After the creation of the first issue, it was relatively easy to continue writing and editing the newsletter, because most of the basic information and structure was contained on the initial word-processing diskette. All that was required was to type the new information, meeting dates, and materials into the original framework.

\section{COMPUTERS-TO-GO PROGRAM}

At the end of the original questionnaire, space was available for any comments or suggestions that faculty members might care to make. Most expressed great excitement and enthusiasm about computers and computing, or personal likes and dislikes regarding specific computer systems. One suggestion struck me as particularly interesting: "Why not buy a number of portable computers and make them available through the audio-visual department on-loan to faculty members for periods of one week at a time?"

It sounded like an excellent idea. I wrote a request for the reallocation of grant funds from travel and guestlecturer accounts to accounts for the purchase of portable computers, software, and modems. The mathemetics and computer-science departments used their veto powers to block the purchase of Apple or IBM-compatible computers and pointed out that no portable computers could 
be purchased on existing state contracts. To circumvent this obstacle, I ordered nonportable computers and traded them internally to a department which had purchased portable computers by mistake. I obtained the enthusiastic support of the media center personnel, who were delighted to distribute the computers and monitor their use, in the same way that they distributed slide projectors and tape recorders. I provided some public-domain software and some representative software packages on a master diskette for each of the computers, and, aside from some political difficulties and red tape, the computers were available for use almost immediately.

The response of the faculty was overwhelming. Faculty members signed up weeks in advance for each of the three computers and reported that it was a pleasure to be able to learn to use them in the privacy of their own homes or offices. Many used the opportunity to become acquainted with computers and subsequently went out and purchased new or used computer systems. With modems, they quickly learned to download data stored in the campus mainframe into their portables and back to the mainframe. Their only complaint was that not enough computers were available.

\section{SECOND-YEAR FUNDING}

The second year of the grant was funded for an incredible $\$ 90,000$. I decided to continue with most of the previous year's activities, but to circulate another questionnaire to assess faculty reactions to the first year's activities and their possible impact on levels of faculty computer literacy. The second questionnaire indicated that faculty computer involvement had increased to a considerable degree, and that faculty computer use was now roughly equally split among Apple, DEC, IBM, and Radio Shack computers. It was clear that the faculty wanted the newsletter and computers-to-go program to continue, but they were less enthusiastic about the workshops.

The newsletter was expanded and continued to be very successful. Another set of workshops, with specific topics chosen by the faculty themselves, continued to draw very low attendance. And, although a considerable amount (70\%) of the grant money was diverted into the VAX system by the mathematics and computer-sciences departments (a problem I had anticipated but had been unable to completely overcome, despite frantic lobbying and obtaining of guarantees), six Compaq portable computers joined the original three Radio Shack computers.

At the end of the second year, the college administration decided not to apply for a third year of support. Surprised by this, I tried to obtain three Quadlink boards to allow the Compaq computers to run the Apple software programs that so many of the faculty desperately wanted to use in the humanities and language departments, and that were not available in any other format. I also tried to obtain a commitment from the college to provide funds to maintain the portable computers and to continue the publication of the newsletter, but the administration claimed that they were unable to do this with college funds.

I hope that these comments will be useful to those who may find themselves responsible for campus-wide faculty computer literacy progrms. Although some obvious mistakes were made, and a lot of energy was expended, the unexpected benefits of the program have included a tremendous increase in faculty computer use on campus, an increase in available computer facilities, and a general level of excitement on campus that I have not seen for years. 